\title{
Green Conversion of Total Lignocellulosic Components of Sugarcane Bagasse to Thermoplastics Through Transesterification Using Ionic Liquid
}

\author{
Shiori Suzuki, ${ }^{\dagger}$ Yosuke Hamano, Stephanie C. Hernandez, Naoki Wada, ${ }^{*}$ and Kenji Takahashi \\ Faculty of Natural System, Institute of Science and Engineering, Kanazawa University, \\ Kakuma-machi, Kanazawa, Ishikawa 920-1192, Japan. \\ * Corresponding author, E-mail: naoki-wada@se.kanazawa-u.ac.jp \\ † Present affiliation: Department of Biomaterial Science, Graduate School of Agricultural and Life Sciences, \\ The University of Tokyo, 1-1-1, Yayoi, Bunkyo-ku, Tokyo 113-8657, Japan
}

\section{Table of Contents}

Figure S1 Molecular weight distribution of Bag-AcDe measured by size extrusion chromatography (SEC) using a $0.01 \mathrm{~mol} \mathrm{~L}^{-1}$ lithium bromide (LiBr) $/ N, N$-dimethyl formamide (DMF) solution as an eluent and polystyrene standards.

Figure S2 Thermogravimetric (TG) curves of Bag-AcDe with different degrees of substitution of the De group ( $\left.\mathrm{DS}_{\mathrm{De}}\right)$.

Figure S3 Melt-flow curves of Bag-AcDe with the different DS $S_{\text {De. }}$ Open circle and cross marks indicate the beginning temperature of melt flow ( $\left.T_{\text {flow }}\right)$ and offset temperature $\left(T_{\text {offset }}\right)$, respectively.

Figure S4 Stress-strain curves of Bag-AcDe as a function of the $\mathrm{DS}_{\mathrm{De}}$ in tensile tests.

Figure S5 DSs of Ac and long-chain acyl groups as a function of the carbon numbers of the longchain acyl groups in the esterified bagasse. The esterified bagasse was synthesized via one-pot and two-step homogeneous transesterification at $80{ }^{\circ} \mathrm{C}$ using 0.25 equiv/ bagasse- $[\mathrm{OH}]$ of vinyl esters and excess amount of isopropenyl acetate (IPAc). Both the reactions were carried out for $30 \mathrm{~min}$.

Figure S6 TG curves of the esterified bagasse with different carbon numbers of the long-chain acyl groups.

Figure S7 Melt-flow curves of the esterified bagasse with different carbon numbers of the longchain acyl groups. Open circle and cross marks indicate $T_{\text {flow }}$ and $T_{\text {offset, }}$ respectively.

Figure S8 Stress-strain curves of the esterified bagasse with different carbon numbers of the longchain acyl groups.

Table S1 Mechanical properties of the esterified bagasse all which were synthesized in this study 


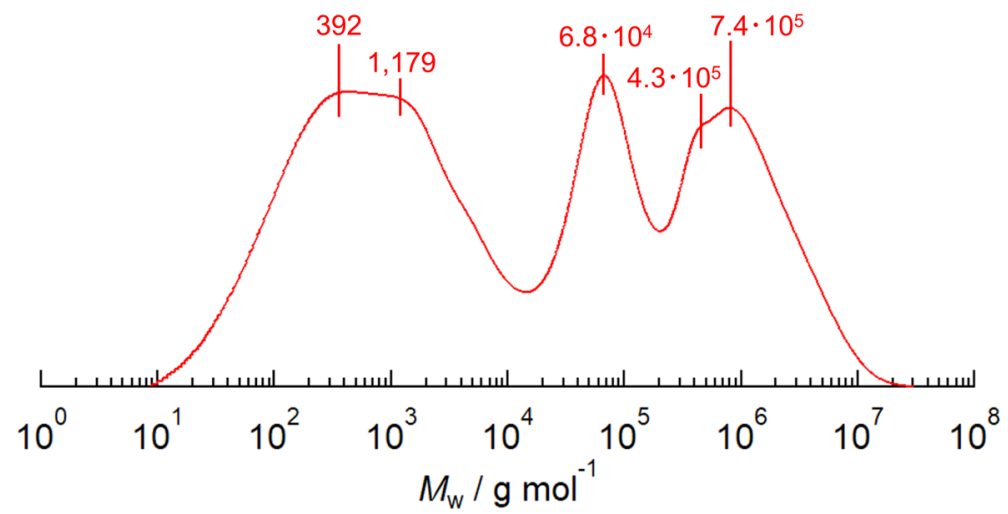

Figure S1. Molecular weight distribution of Bag-AcDe measured by size extrusion chromatography (SEC) using a $0.01 \mathrm{~mol} \mathrm{~L}^{-1}$ lithium bromide ( $\left.\mathrm{LiBr}\right) / N, N$-dimethyl formamide (DMF) solution as an eluent and polystyrene standards. 


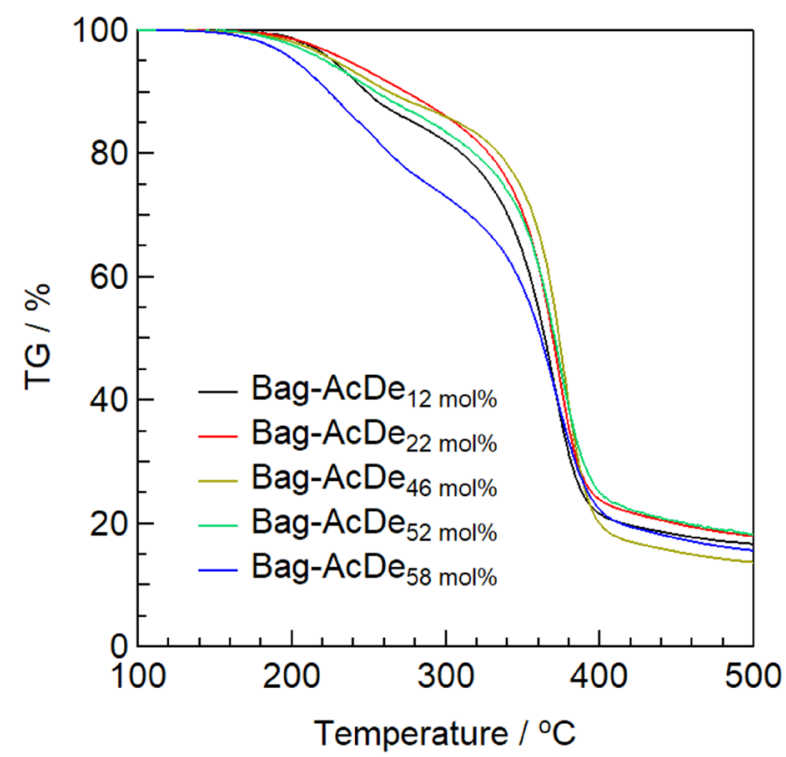

Figure S2. Thermogravimetric (TG) curves of BagAcDe with different degrees of substitution of the De group $\left(\mathrm{DS}_{\mathrm{De}}\right)$.

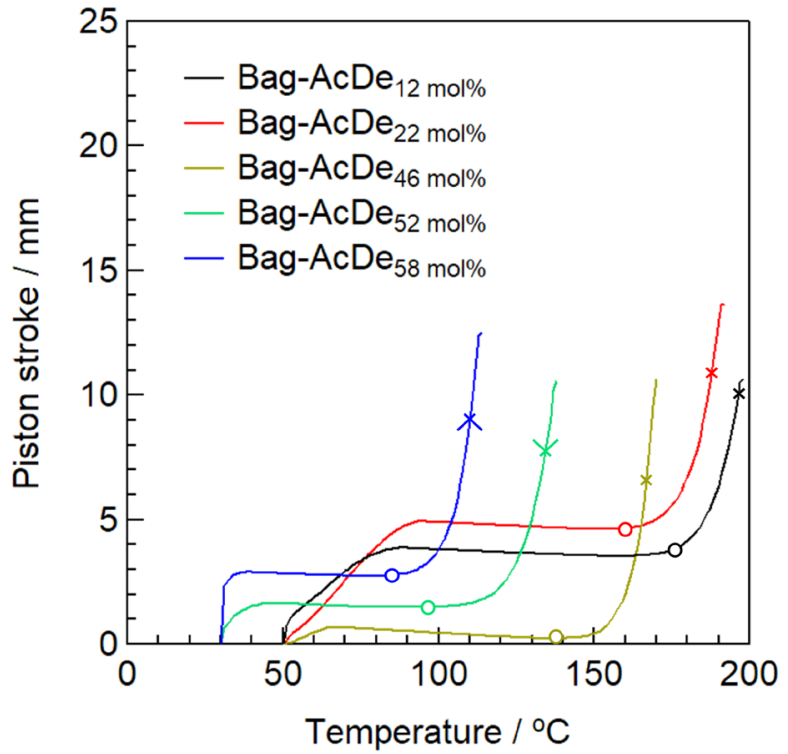

Figure S3. Melt-flow curves of Bag-AcDe with the different $\mathrm{DS}_{\mathrm{De}}$. Open circle and cross marks indicate the beginning temperature of melt-flow ( $\left.T_{\text {flow }}\right)$ and offset temperature $\left(T_{\text {offset }}\right)$, respectively.

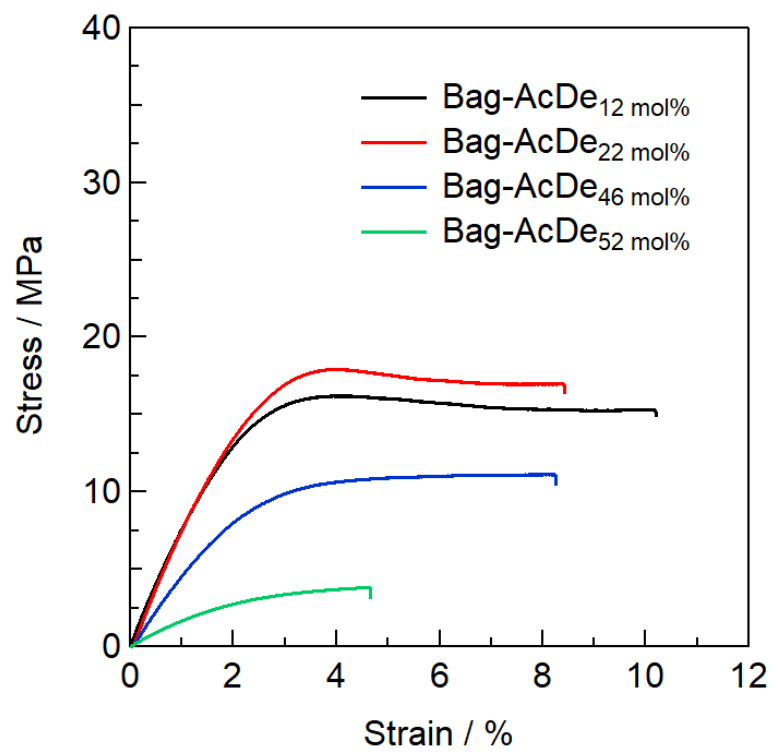

Figure S4. Stress-strain curves of Bag-AcDe as a function of the $\mathrm{DS}_{\mathrm{De}}$ in tensile tests. 


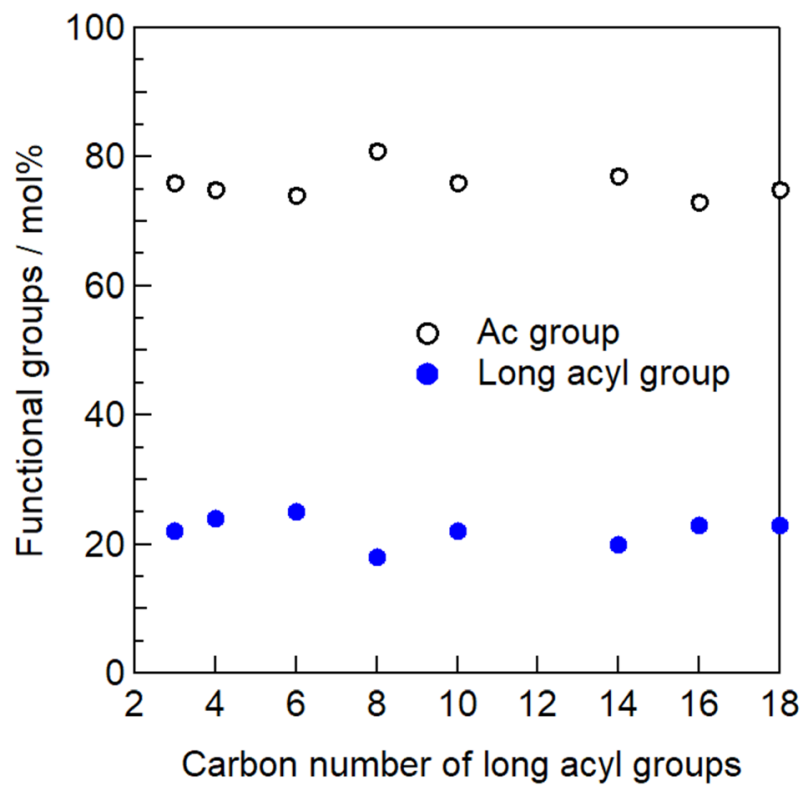

Figure S5. DSs of Ac and long-chain acyl groups as a function of the carbon numbers of the long-chain acyl groups in the esterified bagasse. The esterified bagasse was synthesized via one-pot and two-step homogeneous transesterification at $80^{\circ} \mathrm{C}$ using 0.25 equiv/bagasse-[OH] of vinyl esters and excess amount of isopropenyl acetate (IPAc). Both the reactions were carried out for $30 \mathrm{~min}$. 


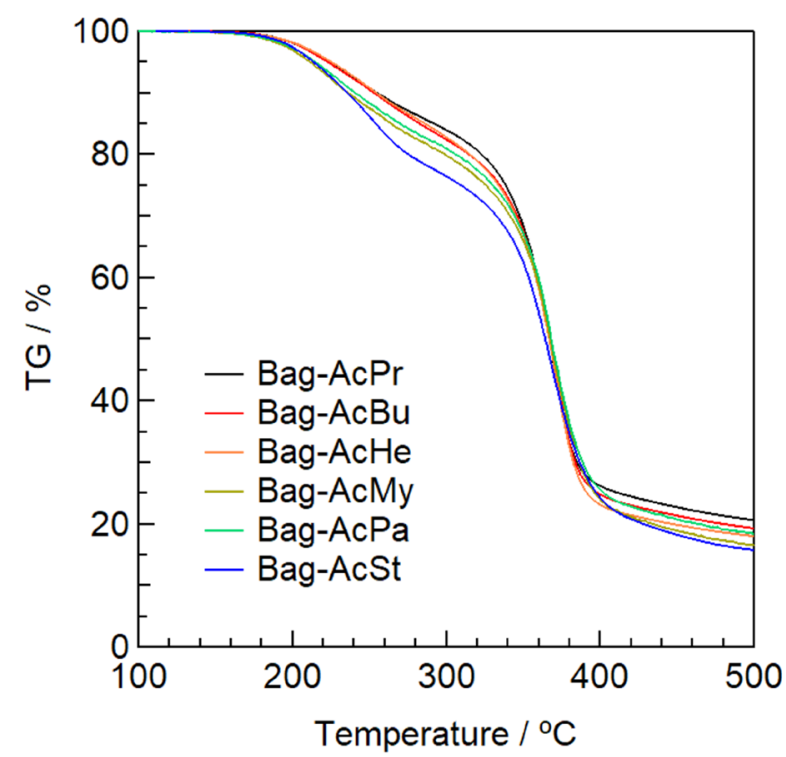

Figure S6. TG curves of the esterified bagasse with different carbon numbers of the long-chain acyl groups.

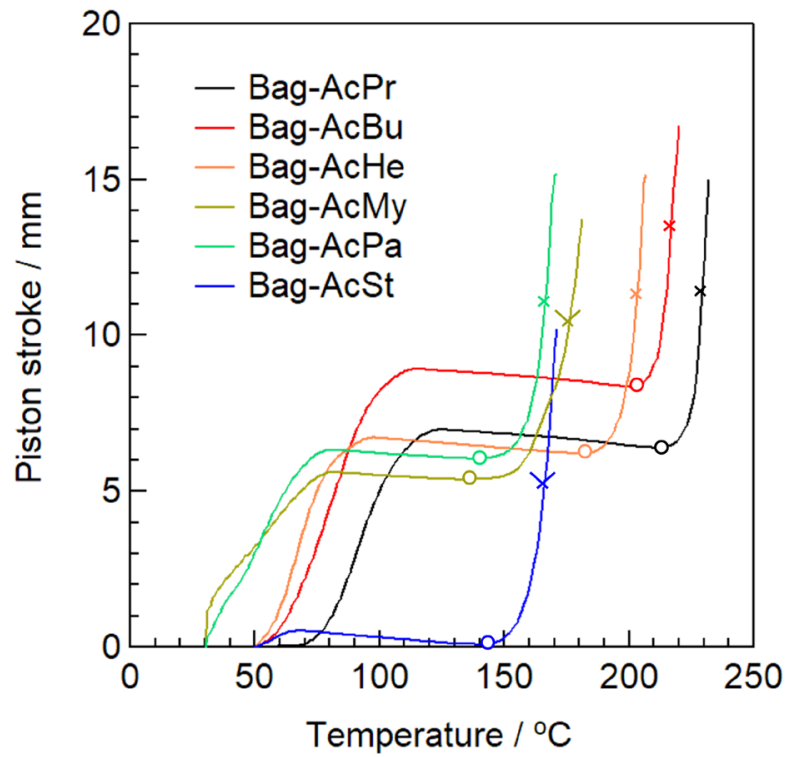

Figure S7. Melt-flow curves of the esterified bagasse with different carbon numbers of the longchain acyl groups. Open circle and cross marks indicate $T_{\text {flow }}$ and $T_{\text {offset, }}$ respectively.

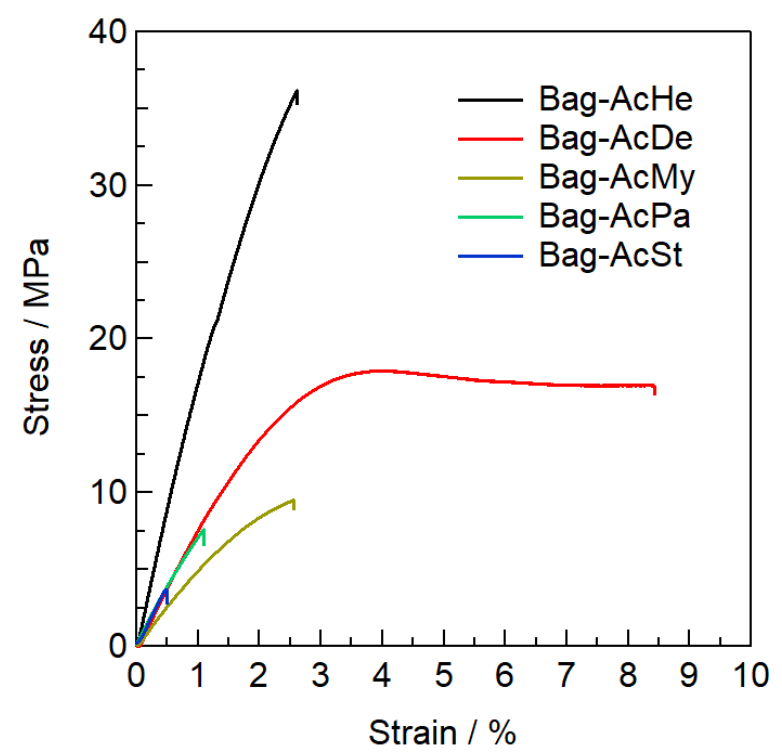

Figure S8. Stress-strain curves of the esterified bagasse with different carbon numbers of the long-chain acyl groups. 
Table S1 Mechanical properties of the esterified bagasse all which were synthesized in this study

\begin{tabular}{lccccccc}
\hline Entry & \multirow{2}{*}{ \# of } & \multicolumn{3}{c}{ DS $/ \%$} & Tensile strength & $\begin{array}{c}\text { Young's modulus } \\
\text { / GPa }\end{array}$ & $\begin{array}{c}\text { Elongation at } \\
\text { break / \% }\end{array}$ \\
\hline Bag-AcHe & 6 & 25 & 74 & 1 & $35.3 \pm 3.6$ & $1.6 \pm 0.04$ & $2.8 \pm 0.1$ \\
Bag-AcDe & 10 & 12 & 86 & 2 & $16.1 \pm 0.9$ & $0.61 \pm 0.05$ & $10.7 \pm 0.4$ \\
& & 22 & 76 & 2 & $17.7 \pm 0.6$ & $0.68 \pm 0.06$ & $8.4 \pm 0.0$ \\
& & 46 & 52 & 2 & $10.7 \pm 0.7$ & $0.45 \pm 0.02$ & $8.1 \pm 0.5$ \\
& & 52 & 46 & 2 & $3.4 \pm 0.7$ & $0.13 \pm 0.01$ & $4.4 \pm 0.3$ \\
Bag-AcMy & 14 & 20 & 77 & 3 & $9.2 \pm 0.6$ & $0.49 \pm 0.01$ & $2.7 \pm 0.6$ \\
Bag-AcPa & 16 & 23 & 73 & 4 & $6.0 \pm 1.2$ & $0.75 \pm 0.04$ & $1.0 \pm 0.1$ \\
Bag-AcSt & 18 & 23 & 42 & 2 & $2.6 \pm 1.2$ & $0.77 \pm 0.06$ & $0.6 \pm 0.1$ \\
\hline
\end{tabular}

